\title{
Pirolisis Katalitik Tandan Kosong Sawit Menjadi Bio-oil dengan Katalis HZSM-5
}

\author{
Sunarno dan Fajril Akbar \\ ${ }^{1}$ Jurusan Teknik Kimia, Fakultas Teknik , Universitas Riau \\ Kampus Binawidya Km 12,5 Panam Pekanbaru \\ E-mail: narnounri@yahoo.com
}

\begin{abstract}
One of the alternative new energy sources is biomass. Biomass can be processes to produce bio-oil. The pyrolysis method was used to convert the palm empty fruit bunch from biomass to bio-oil. The purpose of this research are to study the influence of pyrolysis temperature with bio-oil yield and its properties. Pyrolysis process in slurry reactor with 50 grams palm empty fruit bunch, $500 \mathrm{ml}$ thermo-oil and 2\% HZSM-5 catalyst. Operating temperature variation $\left(290,300,310\right.$ dan $\left.320^{\circ} \mathrm{C}\right)$ have been done. The result show that the optimum temperature obtained at $320^{\circ} \mathrm{C}$ with bio-oil yield is $73.6 \%$. The characterization result of bio-oil product are density is $1.008 \mathrm{gr} / \mathrm{ml}$, viscosity is $12.63 \mathrm{cp}$, flash point $49^{\circ} \mathrm{C}$, and maximum of component obtained is acetic acid with $47.09 \%$.
\end{abstract}

Keywords : Bio-oil ; HZSM-5; New energy source; Pyrolysis

\section{Pendahuluan.}

Salah satu sumber energi alternatif yang dapat diperbaharui dengan pemanfaatan biomassa adalah biooil. Biomassa yang digunakan untuk memproduksi bio-oil dapat diperoleh dari limbah pertanian, hutan, perkebunan, industri dan rumah tangga. Upaya menghasilkan bahan bakar dari biomassa adalah melalui proses pyrolysis (Gayubo dkk, 2005).

Provinsi Riau menghasilkan limbah padat sawit terbesar dengan total luas perkebunan di Riau 1.674.845 Ha dengan produksi kelapa sawit sebesar 5.777.494,99 ton [Dinas Perkebunan Provinsi Riau, 2009]. Tandan kosong sawit (TKS) adalah salah satu produk samping pabrik kelapa sawit yang jumlahnya cukup besar yaitu mencapai $30-35 \%$ dari berat tandan buah segarnya (Hussain dkk., 2006).

Carlson, dkk (2009) melakukan pirolisis sellulosa dalam reaktor fixed bed pyroprobe dengan jenis katalis yang berbeda (ZSM-5, silikat, beta, Y-zeolit dan silikaalumina) pada suhu $600^{\circ} \mathrm{C}$. Diantara katalis tersebut, ZSM-5 mempunyai selektivitas yang tinggi untuk membentuk senyawa aromatik dan paling sedikit karbon yang terbentuk. Dengan katalis ZSM-5 dan rasio katalis/umpan 9,9 diperoleh yield 31,1\%. Zhao, dkk

\section{Metodologi}

Bahan percobaan meliputi : abu sawit, $\mathrm{NaOH}, \mathrm{Al}(\mathrm{OH})_{3}$, tandan kosong sawit (tks), aquades, gas nitrogen dan silinap.

Prosedur percobaan meliputi : persiapan biomassa, pembuatan katalis HZM-5 dan tahap pirolisis. Persiapan biomassanya adalah biomassa berupa TKS yang diambil dari PTPN V PKS Sei Galuh Kab. Kampar dicuci lalu

Perlakuan ini diulangi hingga berat yang diperoleh konstan dan kemudian biomassa dipotong-potong kecil-
(2012) melakukan pirolisis katalitik gamma-valerolactone (yang diperoleh dari hidrolisis lignosellulosa) dengan menggunakan reaktor tubular yang berisi biomassa dan katalis secara simultan. Variabel yang dilakukan suhu pirolisis $\left(400-600^{\circ} \mathrm{C}\right)$ dan jenis katalis (MCM-41; BetaZeolit;ZSM-5;HZSM-5). Hasil terbaik diperoleh dengan menggunakan katalis HZSM-5, suhu $500^{\circ} \mathrm{C}$ diperoleh yield aromatik $41,85 \%$.

Sunarno, dkk (2011) melakukan sintesis katalis HZSM-5 dari abu sawit sawit untuk proses catalytic cracking tandan kosong sawit menjadi bio-oil dengan modifikasi katalis ZSM-5 dengan cara pertukaran ion dengan larutan $\mathrm{NH}_{4} \mathrm{NO}_{3}$ dengan konsentrasi $0.5 \mathrm{M}, 1 \mathrm{M}$, $1.5 \mathrm{M}$, dan $2 \mathrm{M}$ dan didapat sintesis yang bagus dan luas permukaan yang besar dengan konsentrasi $0.5 \mathrm{M}$ $\mathrm{NH}_{4} \mathrm{NO}_{3}$. HZSM-5 yang dimodifikasi dari katalis ZSM-5 pada dasarnya meningkatkan keasaman katalis dan memperluas permukaan katalis yang di harapkan akan memberikan kinerja yang bagus terhadap yield yang dihasilkan. Pada penelitian ini memanfaatkan tandan kosong sawit untuk dipirolisis menggunakan katalis HZSM-5 menjadi bio-oil dengan ratio berat katalis HZSM-5 2\% wt dari berat biomassa dan variasi temperatur pirolisis $290^{\circ} \mathrm{C}, 300^{\circ} \mathrm{C}, 310^{\circ} \mathrm{C}, 320^{\circ} \mathrm{C}$.

Alat yang digunakan meliputi : reaktor pirolisis, oven, viscometer oswald, piknometer, autoclave, heating mantle, teflon dan pengaduk.

dikeringkan di bawah terik matahari setelah itu dikeringkan di dalam oven pada temperatur $105^{\circ} \mathrm{C}$ selama 30 menit.

kecil dengan ukuran potongan $\pm 0,5 \mathrm{~cm}$. Pembuatan katalis HZSM-5 dilakukan dengan cara ZSM-5 dilakukan 
pertukaran ion dengan $\mathrm{NH}_{4} \mathrm{NO}_{3}$ dengan konsentrasi $0,5 \mathrm{M}$ . Pertukaran ion ZSM-5 dengan $\mathrm{NH}_{4} \mathrm{NO}_{3}$ dilakukan pada suhu $80{ }^{\circ} \mathrm{C}$, kecepatan pengaduk $100 \mathrm{rpm}$ selama 12 jam. Untuk basis 10 gr ZSM-5 dilarutkan dengan $300 \mathrm{ml}$ $\mathrm{NH}_{4} \mathrm{NO}_{3}$. HZSM-5 yang terbentuk disaring, dicuci dan dikeringkan pada suhu $90^{\circ} \mathrm{C}$ selama 24 jam. Kemudian HZSM-5 dikalsinasi pada suhu $500^{\circ} \mathrm{C}$ selama 5 jam. Tahap pirolisis dilakukan dengan cara tandan kosong sawit yang telah dipotong-potong kecil sebanyak 50 gram beserta $500 \mathrm{ml}$ silinap (thermo oil) dan katalis HZSM-5 dimasukkan ke dalam reaktor dan diaduk dengan kecepatan pengadukan $300 \mathrm{rpm}$. Proses pyrolysis terhadap bahan dilakukan pada suhu yang bervariasi selama 4 jam tanpa kehadiran oksigen, yaitu dengan mengalirkan gas nitrogen. menggunakan laju alir tetap $(80 \mathrm{ml} / \mathrm{men})$. Uap yang dihasilkan dialirkan melalui kondensor. Setelah pyrolysis dilakukan dihasilkan uap organik dan dikondensasi menjadi bio-oil. Bio-oil ditampung dalam wadah tertentu dan ditimbang berat bio-oil yang didapat. Proses pyrolysis dilakukan dengan memvariasikan temperatur pyrolysis pada : $290,300,310$, dan $320^{\circ} \mathrm{C}$. Serta variasi ratio katalis HZSM-5 adalah $0,1 \%, 2 \%, 3 \%$, dan $4 \%$ dari berat bio massa. Hasil bio-oil optimum yang didapat kemudian dianalisa sacara kimia dan fisika dari bio-oil yang dihasilkan. TKS yang telah dipotong-potong kecil sebanyak 50 gram beserta $500 \mathrm{ml}$ silinap (thermo oil) dan katalis HZSM-5 dimasukkan ke dalam reaktor dan diaduk dengan kecepatan pengadukan $300 \mathrm{rpm}$. Proses pyrolysis terhadap bahan dilakukan pada suhu yang bervariasi selama 4 jam tanpa kehadiran oksigen, yaitu dengan mengalirkan gas nitrogen. menggunakan laju alir tetap $(80 \mathrm{ml} / \mathrm{men})$. Uap yang dihasilkan dialirkan melalui kondensor. Setelah pyrolysis dilakukan dihasilkan uap organik dan dikondensasi menjadi bio-oil. Bio-oil ditampung dalam wadah tertentu dan ditimbang berat biooil yang didapat. Proses pyrolysis dilakukan dengan memvariasikan temperatur pyrolysis pada : 290, 300, 310 , dan $320^{\circ} \mathrm{C}$. Hasil bio-oil optimum yang didapat kemudian dianalisa sacara kimia dan fisika dari bio-oil yang dihasilkan.

\section{Hasil dan Pembahasan.}

Variabel berubah temperatur yang dipilih pada penelitian ini yaitu temperatur $290^{\circ} \mathrm{C}-320^{\circ} \mathrm{C}$. Pemilihan temperatur minimum $290^{\circ}$ didasarkan pada penelitian pendahulu dimana pada temperatur di bawah $300^{\circ} \mathrm{C}$ proses pyrolysis sudah menghasilkan bio-oil dan pada rentang temperatur tersebut komponen kimia dari TKS sudah dapat terdekomposisi, sedangkan pemilihan suhu maksimum $320^{\circ} \mathrm{C}$ (jauh dibawah suhu operasional silinap $280 \mathrm{M}$ yang suhu kerjanya $380^{\circ} \mathrm{C}$ ) bertujuan untuk memastikan tidak terjadi cracking pada thermo-oil. Sebelumnya telah dilakukan penelitian pendahuluan dengan cara pemanasan silinap $280 \mathrm{M}$ dengan menambahkan katalis 1 gram HZSM-5 selama 4 jam pada suhu $340^{\circ} \mathrm{C}$ dialiri gas nitrogen seperti pada proses pyrolysis dan sama sekali tidak menghasilkan kondensat.

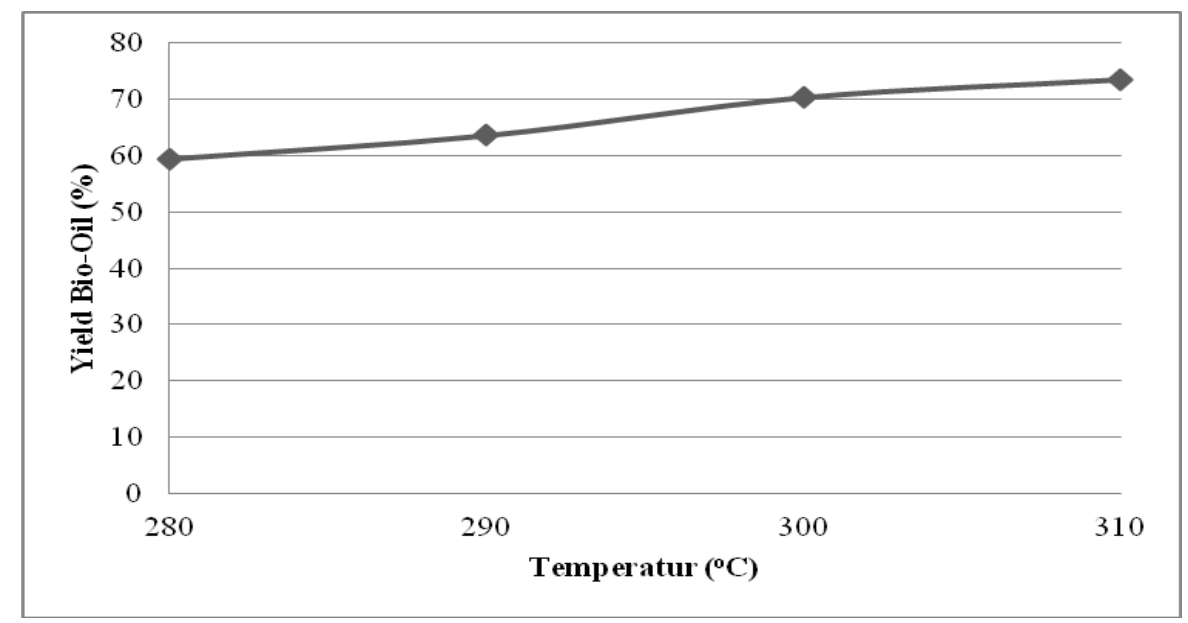

Gambar 1. Hubungan antara temperatur pirolisis dengan yield bio-oil

Dari gambar 1 dapat dilihat hasil optimum yield biooil pada variasi temperatur $320{ }^{\circ} \mathrm{C}$ cukup tinggi dibandingkan dengan temperatur $290^{\circ} \mathrm{C}, 300^{\circ} \mathrm{C}$, dan $310^{\circ} \mathrm{C}$. Persentase yield bio-oil yang dihasilkan pada temperatur $290^{\circ} \mathrm{C}, 300^{\circ} \mathrm{C}, 310^{\circ} \mathrm{C}$ dan $320{ }^{\circ} \mathrm{C}$ berturutturut adalah $59.4 \%, 63.6 \%, 70.4 \%$ dan $73.6 \%$. Hal ini disebabkan temperatur reaksi sangat mempengaruhi terhadap hasil bio-oil. Semakin tinggi temperatur reaksi maka pembentukan bio-oil juga semakin besar, sesuai dengan teori reaksi kimia, dimana kecepatan reaksi akan naik dengan naiknya temperatur. Secara teoritis, yield biooil akan meningkat dengan meningkatnya temperatur dan arang akan berkurang dengan menurunnya temperatur.
Produk pyrolysis diperoleh dari hasil reaksi dekomposisi senyawa-senyawa yang terkandung di umpan. Laju reaksi dekomposisi meningkat seiring dengan peningkatan temperatur dan kandungan air serta senyawa-senyawa volatile akan teruapkan secara cepat dengan jumlah yang lebih besar pula.

Bio-oil yang diperoleh kemudian dikarakterisasi sifatsifatnya secara fisika dan kimia. Karakterisasi fisika yang dilakukan meliputi penentuan massa jenis, viskositas dan titik nyala, sedangkan kimia dilakukan dengan metoda GC-MS. Berikut ini hasil karakterisasi secara fisika menggunakan katalis HZSM-5 2\% dari berat biomassa 
Tabel 1. Perbandingan Hasil Karakterisasi Fisika Bio-oil yang Dihasilkan dengan Standar

\begin{tabular}{|c|c|c|c|c|}
\hline \multirow{2}{*}{ No } & \multirow{2}{*}{ Parameter } & \multirow{2}{*}{$\begin{array}{c}\text { Standar Bio-oil } \\
\text { (Smallwood, 2008) }\end{array}$} & \multicolumn{2}{|c|}{ Bio-oil } \\
\hline & & & Tanpa Katalis & HZSM-5 \\
\hline 1 & Massa Jenis, gr/ml & $0.94-1.2$ & 1.001 & 1.008 \\
\hline 2 & Viskositas, $\mathrm{Cp}$ & $10-150$ & 17.40 & 12.53 \\
\hline 3 & Titik Nyala, ${ }^{0} \mathrm{C}$ & $48-55$ & 51 & 49 \\
\hline
\end{tabular}

Pengujian bio-oil dengan katalis HZSM-5 2\% yang dipilih karena dari variasi katalis HZSM-5 2\% menghasilkan yield lebih banyak dari variasi katalis lainnya. Dari tabel 4.1 dapat dilihat bahwa pengujian dengan katalis HZSM-5 2\% menghasilkan nilai densitas, viskositas, dan titik nyala masing-masing adalah 1.008 gr/ml, $12.53 \mathrm{Cp}$, dan $49^{\circ} \mathrm{C}$. Dengan demikian bio-oil yang dihasilkan dari pyrolysis TKS dengan katalis HZSM-5 memenuhi standar bio-oil karena berada di dalam range standar bio-oil yang ditampilkan. Untuk hasil analisa kimia dari bio-oil digunakan metode GC-MS, dengan sampel yang sama diuji yaitu dengan katalis HZSM-5 $2 \%$. Berikut hasil kromatogram dari sampel tersebut.

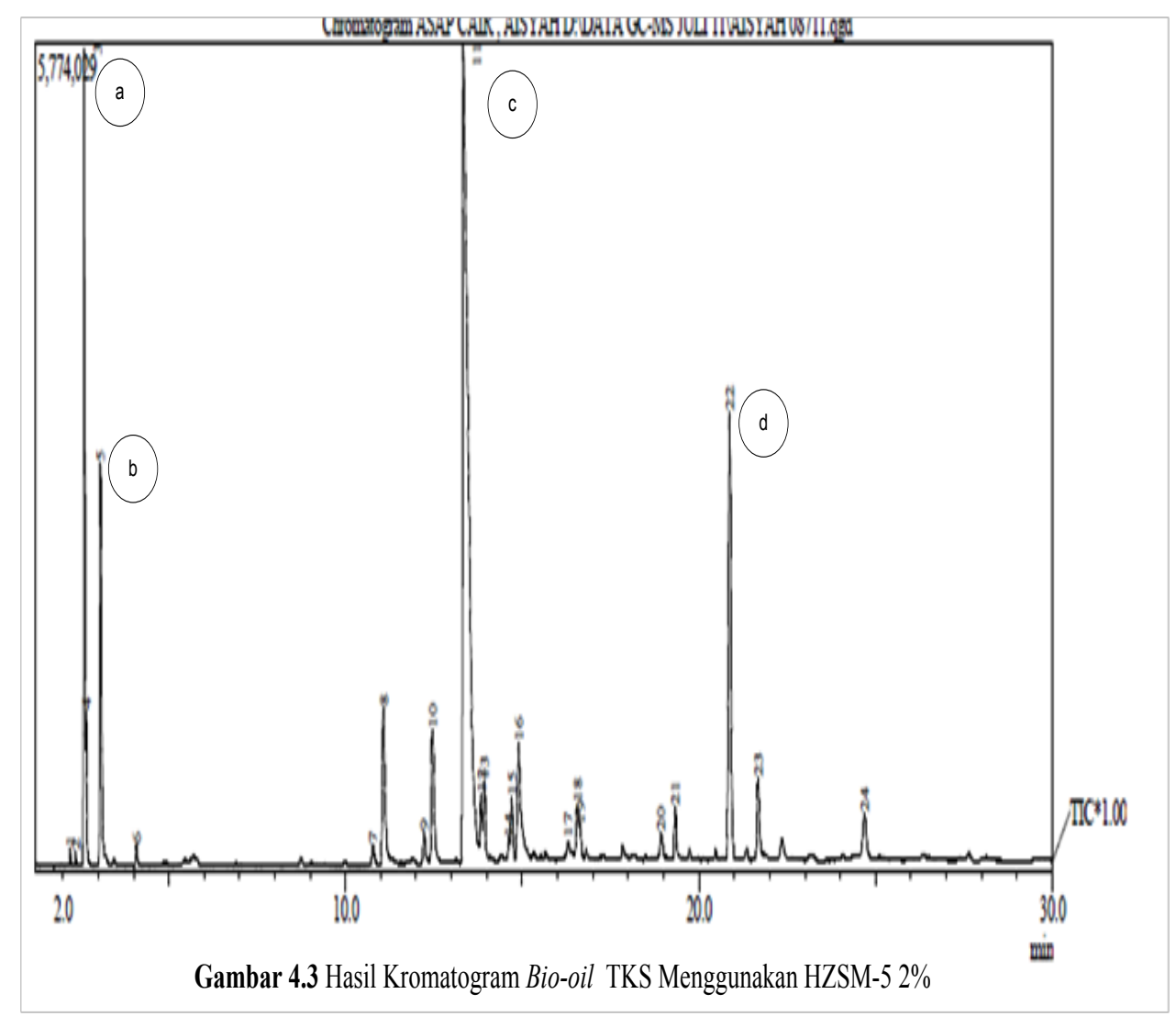

dimana :

$$
\begin{array}{ll}
\mathrm{a}=\text { 2-propanone acetone } & \mathrm{c}=\text { acetic acid } \\
\mathrm{b}=\text { methanol carbinol } & \mathrm{d}=\text { phenol }
\end{array}
$$

Dari gambar 4.3 kromatogram mempunyai 4 puncak yang paling tertinggi. Dari gambar c memiliki puncak yang paling tertinggi dengan luas areanya $47.09 \%$ dibandingkan dengan a,b, dan d dengan luas areanya masing-masing adalah $9.37 \%, 6.67 \%$ dan $11.82 \%$. Di puncak-puncak lainnya pada kromatogram juga terdapat komponen-komponen organik yang diinginkan dari energi alternatif pengganti bahan bakar dari minyak bumi antara lainnya : 2-propanone acetone, 2-methyl furan, 2- furyl methyl keton, formic acid methyl ester, propionic acid dan lain-lainnya, yang senyawa tersebut merupakan turunan dari hidrokarbon dan karboksil . 


\section{IV.Kesimpulan.}

- Yield bio-oil tertinggi diperoleh pada suhu $320^{\circ} \mathrm{C}$ dan rasio berat katalis/bimassa $2 \%$ yaitu $73,6 \%$.

- Karakteristik bio-oil hasil pyrolysis TKS menggunakan katalis HZSM-5 antara lain: densitas $1.008 \mathrm{gr} / \mathrm{ml}$, viskositas $12.63 \mathrm{cp}$, titik nyala $49^{\circ} \mathrm{C}$ dan komponen acetic acid sebesar $47.09 \%$.

\section{Ucapan Terimakasih}

Ucapan terimakasih kepada aisyah dan pihak-pihak yang membantu terlaksananya penelitian.

\section{V.Daftar Pustaka.}

Carlson, T. R., Vispute T. P., dan Huber G. W., 2008, Green Gasoline by Catalytic Fast Pyrolysis of Solid Biomass Derived Compounds,
ChemSusChem, Hal 397- 400, Wiley-VCH Verlag GmbH\& Co. KGaA, Weinheim.

Dinas Perkebunan Provinsi Riau, 2009, Luas Areal Kelapa Sawit Di Provinsi Riau, Laporan Sub Dinas Kelapa Sawit, Pekanbaru.

Gayubo, AG., Aguayo., Atutxa.,Valle., Bilbao., 2005, Undesired Components in the Transformation of Biomass pyrolysis Oil into Hydrocarbons on an HZSM-5 Zeolite Catalyst, Ind Eng Chem, Vol 80, 1244-1251.

Hussain, A., Ani, F.N., Darus, A.N., Ahmed, Z., 2006, Thermogravimetric And Thermochemical Studies Of Malaysian Oil Palm Shell Waste, Jurnal Teknologi, 45(A), 43-53.

Smallwod, 2008, Hydroprocessing of Pyrolisis Bio-oil to Fuel and Chemical, Pacific Northwest National Laboratory, US Departemant of Energy. 